\title{
Mortality and health-related habits in 900 Finnish former elite athletes and their brothers
}

Kontro, Titta Katariina

2018-01

Kontro , T K , Sarna , S , Kaprio , J \& Kujala , U M 2018 , ' Mortality and health-related habits in 900 Finnish former elite athletes and their brothers ', British Journal of Sports Medicine , vol. 52 , no. 2 , pp. 89-95 . https://doi.org/10.1136/bjsports-2017-098206

http://hdl.handle.net/10138/311495

https://doi.org/10.1136/bjsports-2017-098206

cc_by_nc

acceptedVersion

Downloaded from Helda, University of Helsinki institutional repository.

This is an electronic reprint of the original article.

This reprint may differ from the original in pagination and typographic detail.

Please cite the original version. 


\section{Mortality and health-related habits in Finnish former elite athletes and their brothers.}

Titta K. Kontro, ${ }^{1}$ Seppo Sarna, ${ }^{2}$ Jaakko Kaprio, ${ }^{2,3}$ Urho M. Kujala ${ }^{1}$

${ }^{1}$ Faculty of Sport and Health Sciences, University of Jyväskylä, Jyväskylä, Finland

${ }^{2}$ Department of Public Health, University of Helsinki, Helsinki, Finland

${ }^{3}$ Institute for Molecular Medicine Finland (FIMM), University of Helsinki, Helsinki, Finland

Correspondence to: Titta K. Kontro, Faculty of Sport and Health Sciences,

University of Jyväskylä, P.O. BOX 35, 40014 Jyväskylä, Finland;

titta.k.kontro@student.jyu.fi

Key words: ALCOHOL, CHRONIC DISEASE, COHORT STUDY, FORMER ATHLETE, MORTALITY, PHYSICAL ACTIVITY, SMOKING.

Word count: 2983 


\section{ABSTRACT}

Background: There is conflicting evidence on the associations between participation in vigorous sports, health habits, familial factors and subsequent mortality. We investigated allcause mortality and health-related behavior among former elite athletes and their brothers.

Methods: The mortality of Finnish male former elite athletes, who had represented Finland between 1920 and $1965(\mathrm{n}=900)$ and their age-matched brothers $(\mathrm{n}=900)$ was followed from the time when athlete started an elite athlete career until December 31, 2015. The ageadjusted Hazard ratios (HRs) were calculated by a paired Cox proportional hazards model. In 2001 surviving participants ( $\mathrm{n}=199$ athletes and $\mathrm{n}=199$ age-matched brothers) questionnairereported their self-rated health (SRH), physical activity, alcohol consumption and smoking habits.

Results: During the total follow-up period 1296 deaths (72\% of the cohort) occurred. The age-adjusted HRs for all-cause mortality in former athletes was 0.75 (95\% CI 0.65 to 0.87 , $\mathrm{p}<0.001)$ compared to their age-matched brothers. Median age at death was 79.9 years for endurance, 75.9 years for mixed sports, and 72.2 years for power sports athletes, and 77.5, 73.7 and 72.2 years for their age-matched brothers respectively. In 2001, compared to their brothers, former athletes smoked less $(\mathrm{p}<0.001)$, were more physically active $(\mathrm{p}<0.05)$, and rated their health more often as very good $(\mathrm{p}<0.05)$.

Conclusions: Former elite athletes are more physically active, smoke less, have better SRH and live longer than their brothers. Genetic differences between athletes and brothers, aerobic training for endurance elite sports and a healthier lifestyle may all contribute to reduced mortality.

Key words: ALCOHOL, CHRONIC DISEASE, COHORT STUDY, FORMER ATHLETE, MORTALITY, PHYSICAL ACTIVITY, SMOKING. 
3 Observational studies show that certain lifestyle habits, such as hazardous alcohol drinking, 4 cigarette smoking, and low physical activity are important predictors of morbidity and 5 mortality. ${ }^{1}$ Furthermore, self-rated health (SRH) is a predictor of mortality, ${ }^{2}$ and physical 6 activity (PA) is related to better $\mathrm{SRH} \cdot{ }^{3-4}$

7

Regular PA is associated with better functioning and well-being especially at older age, ${ }^{5-6}$ a lower risk for morbidity, ${ }^{7-8}$ and all-cause mortality. ${ }^{9-12}$ Former endurance and mixed sports athletes have lower mortality than the general population, ${ }^{13}$ but previous studies report inconsistent results for power sports athletes. ${ }^{14}$ However, very intense patterns of exercise may increase risk for cardiovascular morbidity and mortality compared to light to moderate amounts of exercise. ${ }^{9,15}$

There is no irrefutable evidence on a causal relationship between physical activity in adulthood and mortality, either in animal experiments, or randomized controlled intervention studies with healthy individuals. ${ }^{16}$ Cardiorespiratory fitness (CRF) is as a strong, independent predictor of all-cause and disease-specific mortality ${ }^{17}$ and high level of CRF is associated with a lower risk of all-cause and cardiovascular disease (CVD) mortality, in both rats ${ }^{18}$ and humans. ${ }^{19,20}$ It has previously been widely reported that former athletes have lower morbidity and mortality compared to general population, ${ }^{12}$ which may be due to their genetic background, increased PA levels or other better health habits. ${ }^{7-8,13}$ Former athletes are more physically active and smoke less than controls, ${ }^{12}$ while former ${ }^{21-22}$ or current athletes consume more alcohol than non-athletes. ${ }^{23}$ 
In contrast to our earlier studies on a cohort of former elite athletes before, ${ }^{11,13}$ but we use brothers as control rather than unrelated healthy men. We selected brothers as controls because they are genetically related and generally share the same family environment in childhood. Thus, they may serve to control for experiences and exposures that cannot be assessed when using unrelated controls. The aim of this study was to investigate whether allcause mortality and the development of behavioral and biological risk factors differ between athletes and their brothers in later life. This unique study reveals novel data on the associations between PA, familial factors, health-related behaviour, and mortality.

\section{METHODS}

\section{Participants}

An original cohort of former elite athletes $(n=2657)$ was formed by identifying men who had represented Finland between 1920 and 1965 at least once at the Olympic Games, European or World championships, or inter-country competitions. ${ }^{12}$ The athlete's brothers $(n=2674)$ has been collected from local parish registry data in early 1980s.

We excluded 219 athletes and 1774 brothers due to missing or uncertain information on date of birth, date of death or death before 1936. We also excluded brothers who had died before the time when the athlete started an elite athlete career. After including only athletes who had brothers with complete data, the final study population $(n=2755)$ consisted of 900 former male athletes and their 1855 brothers (Table 1 and Figure 1). Former elite athletes $(n=900)$ and their individually matched brothers who were closest in age ( $\mathrm{n}=900)$ were included in the primary mortality analysis (paired Cox regression model). The former male athletes were 
classified according to sports and sports-specific aerobic fitness characteristics into the following three groups: ${ }^{12}$ endurance sports $(n=217)$, mixed sports $(n=307)$ and power sports $(\mathrm{n}=376)$ (individual sports are given in Table 1 and Figure 1). We also did a sensitivity analysis based on former elite athletes $(n=900)$ and all of their brothers $(n=1855)$ (Figure 1).

Socioeconomic status was defined by five occupation-based social class groups: upper white collar (executive and professionals), lower white collar workers (clerical work and equivalent), skilled workers, unskilled workers and farmers. ${ }^{24}$ Data were collected partly from the Central Population Registry of Finland and partly from questionnaires based on the occupation in which they had practiced the longest. The occupational group distribution of athletes differed from that of brothers $\left(\mathrm{p}<0.001, \chi^{2}\right.$-test) (Supplementary Table 1$)$.

The data consisted of time and cause of death until December 31, 2015. The main outcome variable was total all-cause mortality, and it was analyzed by using Cox regression model. Secondly, the distributions of cause-specific deaths were analyzed by using cross-tabulations. Mortality data were collected from the National Death Register of Statistics Finland (causes of death; http://www.stat.fi/til/ksyyt/2005/ksyyt_2005_2006-10-31_luo_002.html).

\section{Comparison of athletes and brothers: the questionnaire study 2001}

In 2001 a postal questionnaire was sent to surviving elite athletes and brothers resident in Finland eliciting information on health, lifestyle and sociodemographic characteristics. In 2001, 460 of 900 former athletes and 392 of their 900 age-matched brothers were alive; there were 199 athletes who with their 199 age-matched brothers responded to the questionnaire. We also did sensitivity analysis for the athletes $(n=199)$ and all of their brothers $(n=322)$ 
(Figure 1). Furthermore, we used population controls $(n=416)$, who were the unrelated controls in the present cohort. ${ }^{25}$

\section{Questionnaire-based covariates}

Body mass index (BMI) was calculated as self-reported weight $/ \mathrm{height}^{2}\left(\mathrm{~kg} / \mathrm{m}^{2}\right)$. The volume of PA (MET-hours/day) was based on responses to three structured questions on intensity, duration and frequency of activity using a previously validated method. ${ }^{10,26}$ The participants were classified into tertiles of PA. Sedentary time was assessed by continuous variable called as sitting time (hours/day).

Based on a detailed smoking history, we define smoking status as never, former, current or occasional smokers. Those who have never smoked more than 100 cigarettes lifetime were defined as never smokers. Former smokers had smoked more than 100 cigarettes in their lifetime, who had smoked regularly, but had not smoked during the last month. Current smokers were regular (daily or almost daily) smokers at the time of data collection. ${ }^{27}$ Occasional smokers were men who smoked no more than 2 cigarettes in a week ${ }^{28}$ or had last smoked 2-30 days ago. ${ }^{29}$ Among current or ex-smokers, nicotine dependence was assessed using the Heaviness of Smoking Index (HSI), i.e. 2 items of the Fagerström Test for Nicotine Dependence (FTND): the number of cigarettes per day and the time to the first cigarette in the morning. ${ }^{30}$ The HSI sum score ranges from $0-6$, reflecting the degree of physical dependence, and accounts for about $80 \%$ of the variance in the FTND. ${ }^{25,31}$

Alcohol use was assessed by questions on total alcohol consumption and heavy drinking occasions (HDO). Alcohol consumption based on quantity-frequency measures of beverage 
use was converted into grams of pure alcohol per month as previously reported. ${ }^{29}$ Drinkers were classified as abstainers and light ( 3 or fewer drinks per week), moderate (more than 3 but not more than 14 drinks per week) and heavy drinkers (on average more than 2 drinks a day). ${ }^{32}$ Heavy drinking occasions (HDO) were asked by question on the frequency of drinking 5 or more alcoholic drinks on a single occasion in the past 30 days. ${ }^{33}$ A HDO variable had three categories: no HDO, HDO 1-2 times a month and HDO at least weekly.

Self-rated health (SRH) was measured by asking the participants to rate their own health status at this moment on a previously validated ${ }^{2}$ 5-point Likert scale: 1) very good, 2) quite good, 3) average, 4) quite poor and 5) poor. Self-reported current symptoms and a history of physician-diagnosed chronic diseases were grouped as dichotomous variables, such as any chronic disease, hypertension with medication, angina pectoris, myocardial infarct, diabetes, kidney disease, gastric ulcer, asthma and osteoarthritis. A history of any sports injury- and Achilles tendinitis- or total rupture - was queried.

Activities of Daily Living (ADL) and Instrumental Activities of Daily Living (IADL) were assessed by a total of nine items. ${ }^{34}$ These national survey questions were modified from classification of functional capacity. ${ }^{35-36}$

Self-rated mood was defined by two partial scales (6 depression items and 6 anxiety items) of the short stress symptom survey extracted from the Brief Symptom Inventory-53 (BSI-53). ${ }^{37}$

\section{Statistical analysis}


125 The descriptive data are presented as the mean and standard deviation (SD) or 95\% 126 confidence intervals (CI) if distributed normally; otherwise the results are shown as the

127 median. The differences in the distributions of the categorical variables among different sports groups and brothers were examined using cross-tabulations with the Chi-square $\left(\chi^{2}\right)$ 129 test.

The follow-up of all-cause mortality of each athlete and brother started from the time when the athlete was an elite athlete, and continued until the date of death (outcome event), date of emigration (censoring event) or end of follow-up on December 31, 2015. A paired Cox proportional hazards model was used to calculate age-adjusted hazard ratios (HRs) with 95\% CIs for all-cause mortality of former athletes relative to their brothers. Post hoc analysis taking into account the number of comparisons was used to compare statistical differences between specific sports groups. We also adjusted the mortality analysis for family clustering in the subgroup analysis based on all questionnaire 2001 respondents. The Cox regression assumptions were tested by using Schoenfeld residuals (ph-test in Stata) and by plotting "loglog plots".

The 2001 questionnaire data was mainly analyzed using non-parametric Wilcoxon`s signed rank test (a matched-pair analysis) for ordinal or continuous variables and McNemar`s test (a matched-pair analysis) for nominal variables to analyze the differences between each athlete and the age-matched brother. The Chi-square $\left(\chi^{2}\right)$-test and The Mann-Whitney-U-test were used to compare differences between athletes and all their brothers, because some of the

147 variables were not normally distributed and variances were not equal. Homogeneity of variances were assessed using Levene`s test and normality using Kolmogorov-Smirnov`s test 149 $(\mathrm{p}<0.05)$ 
P-values $<0.05$ were considered statistically significant. Statistical analyses were performed using SPSS statistical software (version 24.0 for Windows; SPSS Inc., Chicago, IL) and Stata 14.0 (Stata Corp, College Station, Texas, USA).

\section{RESULTS}

\section{Mortality data}

The final sample for mortality analysis included 900 former elite athletes and their 900 agematched brothers. Mean age at inclusion was 24.8 years and mean year of inclusion was 1943, and median follow-up time was 52.0 years (ranging from 0.1 to 83.4 years). Study group characteristics are shown in Table 1. During the total follow-up period 1296 deaths occurred; $72.1 \%(n=649)$ of the athletes and $71.9 \%(n=647)$ of the brothers died. Natural causes accounted for death in $92.2 \%(\mathrm{n}=1085)$ of the participants. The most common specific cause of death was ischemic heart disease (IHD), which occurred in $35.5 \%(n=418)$ of all men (34.3\% ( $\mathrm{n}=219)$ athletes, 36.9\% ( $\mathrm{n}=199)$ brothers) (Supplementary Table 2).

Median age at death among the former athletes (75.9 years, 95\% CI 75.1 to 76.7) was statistically significantly higher than among brothers (73.0 years, 95\% CI 72.0 to 74.0 ). Median age at death among endurance (79.9 years, 95\% CI 79.1 to 80.7$)$ and mixed sports athletes (75.9 years, 95\% CI 75.1 to 76.7$)$ was statistically significantly higher than among power sports athletes (74.1 years, $95 \%$ CI 73.3 to 75.0 ) (Table 2).

The age-adjusted hazard ratios (HRs) for all-cause mortality in former athletes was 0.75 (95\% CI 0.65 to $0.87, \mathrm{p}<0.001$ ) compared to their age-matched brothers (Table 2). In a 
175 subgroup analysis, compared to their age-matched brothers HR for all-cause mortality was $0.61(95 \%$ CI 0.45 to $0.82, \mathrm{p}=0.001)$ for endurance sports athletes, 0.85 (95\% CI 0.65 to 1.10 ,

177 $\mathrm{p}=0.220$ ) for mixed sports athletes and 0.78 (95\% CI 0.62 to $0.98, \mathrm{p}=0.033$ ) for power sports athletes (Table 2). In the sensitivity analysis the age-adjusted HRs for all-cause mortality in former athletes $(n=900)$ was $0.76(95 \%$ CI 0.67 to $0.86, p<0.001)$ compared to all their brothers $(\mathrm{n}=1855)$ (Supplementary Table 3).

We found that in the individual-based non-pairwise analysis the assumptions of Cox regression model were violated suggesting a lower mortality of athletes at younger ages but less so at older ages. We divided the follow up time into two periods: age at entry to median age at death and median age at death to December 31, 2015. The age-adjusted pairwise HRs for all-cause mortality in former athletes was 0.68 (95\% CI 0.57 to $0.82, \mathrm{p}<0.001)$ compared to their age-matched brothers in the first follow-up period and 0.74 (95\% CI 0.57 to 0.98 , $\mathrm{p}=0.03$ ) in the second period. The results of the sensitivity analysis were consistent with the results of age-matched pair analysis, but there was no difference in mortality during the later period (Supplementary Table 4).

We also calculated adjusted HRs for all-cause mortality for all questionnaire 2001 respondents until 2015. There were no differences in HRs between groups (Supplementary Table 5).

\section{Questionnaire data}

There were no statistically significant differences in anthropometric data between former athletes and brothers (Table 3). Mean MET-hours/month in 2001 were significantly higher 
among former athletes than their age-matched brothers (4.4. vs. 3.2 MET-hours/day) $(\mathrm{p}<0.05)$. More athletes $(11.2 \%)$ than brothers $(2.1 \%)$ participated in vigorous PA $(\mathrm{p}<0.05)$. The athletes sat less than brothers $(\mathrm{p}<0.001)$ (Table 3).

Former athletes smoked less than their age-matched brothers $(\mathrm{p}<0.001)$, and among smokers the athletes were less nicotine-dependent. No significant differences in alcohol use were observed (Table 3). Former athletes self-reported their health as very good much more frequently $(20.6 \%)$ than their brothers $(8.6 \%)(\mathrm{p}<0.05)$. There were no statistically significant differences in specific chronic diseases, such as hypertension, heart disease, diabetes or asthma between former athletes and their brothers. However, brothers reported more chronic disease than former athletes $(\mathrm{p}<0.05)$. Former athletes had more self-reported physiciandiagnosed sports injuries and Achilles tendinitis than their brothers $(\mathrm{p}<0.05)$ (Table 4). There were no differences in mobility, physical or psychosocial functioning of daily living between former athletes and their brothers, except travelling by public transport. Mean of anxiety score was higher among brothers than among former athletes $(\mathrm{p}<0.05)$, and brothers felt themselves more restless and excited than former athletes $(\mathrm{p}<0.05)($ Table 4$)$.

We also did sensitivity analysis based on former elite athletes ( $n=199)$, all of their brothers $(\mathrm{n}=322)$ and population control $(\mathrm{n}=416)$ (Supplementary Tables 6 and 7). The results were consistent with the results of age-matched pair analysis.

\section{DISCUSSION}

\section{Principal findings}


Former elite athletes survived 2-3 years longer than their brothers, with the largest difference seen for endurance athletes and none for power athletes. However, there was no difference in the risk of all-cause mortality between athletes and all of their brothers at older age. Overall SRH and health-related lifestyle habits of former elite athletes were better than those of their brothers. However, there were no significant differences in mobility, physical or psychosocial functioning of daily living between former athletes and their brothers who responded to the 2001 questionnaire. The brothers showed evidence for worse mood than athletes.

\section{Strengths and limitations of our study}

This unique long-term follow-up study revealed novel data on associations between healthrelated behaviour, and mortality among individuals from the same family, who share both genes and childhood environment. Valid death register data covering all participants was the strength of this study. Although our questions on $\mathrm{PA},{ }^{26}$ smoking $^{38}$ use of alcohol ${ }^{39}$ have been previously validated, self-reported data on health-related behaviors is only based on an agematched respondents subgroup from 2001. We have neither exact data on level of PA across the lifespan nor health at younger ages among brothers. A partly insufficient data of SES or causes of death among brothers could be considered as a limitation. However, athletes and their brothers are from same family and differences in SES may be caused by athletic career. We do not exactly know how well the results can be generalized to non-athletes, women or today`s athletes from different sports groups or cultures, such as NFL players ${ }^{40-41}$ or U.S basketball players ${ }^{42}$ who seem to have high prevalence of clinically significant cardiac abnormalities.

\section{Comparisons with other studies}


Observational studies in general have found that regular PA is associated with a lower risk for

250 all-cause mortality, ${ }^{9-11}$ but high amounts of exercise among poorly trained individuals may

251

252

253 increase risk for CVD morbidity and mortality compared to light to moderate amounts of exercise. ${ }^{9,15}$ Studies of elite athletes, i.e, among well-trained sportsmen do not support that. The pattern of training and frequency of high-intensity exercise needs to be taken into account.

Our study extends previous findings that former athletes, especially former endurance sports athletes, have higher longevity and lower mortality than the general population. ${ }^{12-13}$ In general, runners have a $25 \%-40 \%$ reduced risk of premature mortality and live approximately 3 years longer than non-runners ${ }^{43}$. Although high lifelong exercise volume among surviving athletes is associated with coronary artery calcifications, the atherosclerotic plaques of the most active athletes have a more benign composition ${ }^{44}$. The evidence is mostly based on observational follow-up studies, one limitation of which is the difficulty of controlling for genetic or other selection bias. There is no an irrefutable evidence on a causal relationship between PA in adulthood and mortality. Based on previous studies on twins and former elite athletes $^{8,10}$ and both animal and human findings, ${ }^{16-17,19}$ it could be proposed that some of the association between high PA and low mortality is explained by familial or genetic factors. Despite this, we see a lower mortality in former athletes, especially at younger age compared to their brothers knowing the limitation that some of the brothers may have had health concerns at the beginning of our follow-up.

Our findings support previous studies that have shown athletes were more physically active than controls. ${ }^{12,22}$ But we also observed that brothers were more physically active and went in 
273 for more vigorous activities than population controls (Supplementary Table 6), suggesting a

274 familial contribution to PA that probably originated prior to the elite athletes career.

275

Though brothers smoked more than former athletes, there was no difference in alcohol use.

277 Former athletes are known to smoke less than controls, ${ }^{12,22}$ and we find that brothers also

278 smoked less than population (Supplementary Table 6). It has been found that persistent 279 physical inactivity in adolescence relates to adult smoking, even after familial factors are 280 taken into account. ${ }^{45}$

There were better SRH and less chronic diseases among former athletes in accordance with healthy life expectancy. However, brothers had less chronic diseases than population controls (Supplementary Table 7). There was no difference in disability, possibly because those with highest disability may not be able to respond to questionnaire. As earlier discussed both athletes and brothers were physically active, which could partly explain that no differences were found in functioning. Observational studies have found that regular PA is associated with better functioning and well-being especially at older age,${ }^{5-6}$ and a lower morbidity. ${ }^{7-8}$

\section{Future directions}

Our results are based on men who were former athletes 50 or more years ago. So, it is important to investigate the associations between PA, familial factors, health-related behaviour, and mortality among today's athletes, non-athletes or women. Traditional and genetically informative designs are needed to investigate how elite performance related to future health outcomes. 


\section{CONCLUSIONS}

Former elite athletes have lower premature mortality than their brothers, and correspondingly better SRH and health-related lifestyle habits. Former endurance sports athletes and their brothers had reduced mortality compared to power sports athletes and their brothers. In conclusion, our findings support previous findings for a role of genetic or childhood family factors in determining high aerobic fitness and reduced mortality.

\section{What are the new findings?}

- Former elite athletes survived 2-3 years longer than their brothers.

- There was no difference in the risk of all-cause mortality between athletes and all of their brothers at older age.

- Overall SRH and health-related lifestyle habits of former elite athletes were better than those of their brothers.

\section{Contributors}

SS, JK and UMK collected the data. TKK and UMK analyzed the data. TKK drafted the manuscript. All authors contributed to study design, and the revision of the manuscript, and accepted the final version.

\section{Funding}

311 This study was funded by departmental funds of the University of Helsinki and University of

312 Jyväskylä. Jaakko Kaprio was supported by the Academy of Finland (grants \# 265240,

$313 \& 263278)$. There was no conflict of interests.

\section{Competing interest}

315 None.

\section{Ethical approval}

317 This study was conducted according to good clinical and scientific practice and the 318 Declaration of Helsinki. The authors declare that the results of this study are presented 
319 clearly, honestly, and without fabrication, falsification or inappropriate data manipulation.

320 Approval for register data collection was given by the Ministry of Social Affairs and Health

321 in Finland, and Statistics Finland. All the participants gave informed consent by returning the

322 questionnaires, which were accompanied by a cover letter explaining the purpose of the study.

\section{Data sharing}

324 The former athletes are well known persons in Finnish society; hence the data cannot be

325 openly shared. Researchers are encouraged to contact the authors and we will make every 326 effort to accommodate additional analyses.

327

328

329

330

331

332

333

334

335

336

337

338

339

340

341

342

343

344

345

346

347

348

349

350

351 


\section{REFERENCES}

1. Lim SS, Vos T, Flaxman AD, et al. A comparative risk assessment of burden of disease and injury attributable to 67 risk factors and risk factor clusters in 21 regions, 1990-2010: a systematic analysis for the Global Burden of Disease Study 2010. Lancet 2012;380,2224-60.

2. Idler EL, Benyamini Y. Self-rated health and mortality: a review of 27 community studies. J Health Soc Behav 1997;38:21 - 37.

3. Abu-Omar K, Rütten A, Robine JM. Self-rated health and physical activity in the European Union. Soz Praventiv Med 2004;49(4):235-42.

4. Södergren M, Sundquist J, Johansson SE, Sundquist K. Physical activity, exercise and self-rated health: a population-based study from Sweden. BMC Public Health 2008;8:352.

5. King

AC, Pruitt

LA, Phillips

W, Oka

$\mathrm{R}$, et

al.

Comparative effects of two physical activity programs on measured and perceived physical functioning and other health-related quality of life outcomes in older adults. $J$ Gerontol A Biol Sci Med Sci 2000 Feb;55(2):M74-83.

6. Paterson DH, Warburton DE. Physical activity and functional limitations in older adults: a systematic review related to Canada's Physical Activity Guidelines. Int J Behav Nutr Phys Act 2010;11(7):38. doi: 10.1186/1479-5868-7-38.

7. Gajewski AK, Poznanska A. Mortality of top athletes, actors and clergy in Poland: 1924-2000 follow-up study of the long-term effect of physical activity. Eur $J$ Epidemiol 2008;23(5):335-40.

8. Kujala UM, Marti P, Kaprio J, et al. Occurrence of chronic disease in former top-level athletes.Predominance of benefits, risks or selection effects? Sports Med 2003;33(8),553-61.

9. Eijsvogels TM, Molossi S, Lee DC, et al. Exercise at the Extremes: The Amount of Exercise to Reduce Cardiovascular Events. J Am Coll Cardiol 2016;26:67(3):316-29.

10. Kujala UM, Kaprio J, Sarna S, et al. Relationship of leisure-time physical activity and mortality. The Finnish twin cohort. JAMA 1998;279:440-4. 
11. Samitz G, Egger M, Zwahlen M. Domains of physical activity and all-cause mortality: systematic review and dose-response meta-analysis of cohort studies. Int J Epidemiol 2011;40(5):1382-400.

12. Sarna S, Sahi T, Koskenvuo M, et al. Increased life expectancy of world class male athletes. Med Sci Sports Exerc 1993;25(2):237-44.

13. Kettunen JA, Kujala UM, Kaprio J, et al. All-cause and disease-specific mortality among male, former elite athletes: an average 50-year follow-up. Br J Sports Med 2015;49(13):893-7.

14. Clarke PM, Walter SJ, Hayen A, et al. Survival of the fittest: retrospective cohort study of the longevity of Olympic medallists in the modern era. Br J Sports Med 2015;49(13):898-902.

15. Kim JH, Baggish AL. Strenuous Exercise and Cardiovascular Disease Outcomes. Curr Atheroscler Rep 2017;19(1):1-8. doi: 10.1007/s11883-017-0636-3

16. Harber MP, Kaminsky LA, Arena R, et al. Impact of Cardiorespiratory Fitness on AllCause and Disease-Specific Mortality: Advances Since 2009. Prog Cardiovasc Dis 2017;60:11-20.

17. Karvinen S, Waller K, Silvennoinen M, et al. Physical activity in adulthood: genes and mortality. Sci Rep 2015;5:18259. doi: 10.1038/srep18259.

18. Koch LG, Kemi OJ, Qi N, et al Intrinsic Aerobic Capacity Sets a Divide for Aging and Longevity. Circ Res 2011;109(10):1162-72.

19. Lavie CJ, Arena R, Swift DL, et al. Exercise and the cardiovascular system: clinical science and cardiovascular outcomes. Circ Res 2015;117(2):207-19.

20. Kodama S, Saito K, Tanaka S, et al. Cardiorespiratory fitness as a quantitative predictor of all-cause mortality and cardiovascular events in healthy men and women: a meta-analysis. JAMA 2009;301(19):2024-35.

21. Batista CHX, Soares JM. Is athletic background associated with a future lower prevalence of risk factors for chronic disease? J Exerc Sci Fit 2014;12(2):47-54.

22. Kontro TK, Sarna S, Kaprio J, Kujala UM. Use of alcohol and alcohol-related morbidity in Finnish former elite athletes. Med Sci Sports Exerc 2017;49(3),492-9. 
23. Martens MP, Dams-O'Connor K, Beck NC. A systematic review of college studentathlete drinking: prevalence rates, sport-related factors, and interventions. J Subst Abuse Treat. 2006;31(3):305-16.

24. Finland Central Statistical Office. Alphabetical list of occupations and classification of social class. Helsinki: Finland Central Statistical Office; 1972. (Paper version available from authors).

25. Bäckmand H, Kujala U, Sarna S, et al. Former athletes' health-related lifestyle behaviours and self-rated health in late adulthood. Int J Sports Med 2010;31(10):7518.

26. Waller K, Kaprio J, Kujala UM. Associations between long-term physical activity, waist circumference and weight gain: a 30-year longitudinal twin study. Int J Obesity 2008;32(2):353-61.

27. Kaprio J, Koskenvuo MA. prospective study of psychological and socioeconomic characteristics, health behaviour and morbidity in cigarette smokers prior to quitting compared to persistent smokers and non-smokers. J Clin Epidemiol 1988;41:139-50.

28. Paavola M, Vartiainen E, Puska P. Smoking cessation between teenage years and adulthood. Health Educ Res 2001;16:49-57.

29. Luoto R, Uutela A, Puska P. Occasional smoking increases total and cardiovascular mortality among men. Nicotine Tob Res 2000;2:133-9.

30. Haddock CK, Lando H, Klesges RC, et al. A study of the psychometric and predictive properties of the Fagerström Test for Nicotine Dependence in a population of young smokers. Nicotine Tob Res 1999;1:59 - 66.

31. Romanov K, Rose RJ, Kaprio J, et al. Self-reported alcohol use: a longitudinal study of 12954 adults. Alcohol Alcohol Suppl. 1987;1:619-23.

32. Järvenpää T, Rinne $O$, Koskenvuo $M$, et al. Binge drinking in midlife and dementia risk. Epidemiol 2005;16(6):766-71.

33. Substance Abuse and Mental Health Services Administration. Results from the 2004 National Survey on Drug Use and Health: National Findings. Available online at:http://www.oas.samhsa.gov/NSDUH/2k4NSDUH/2k4results/2k4results.htm\#fig7.3 (accessed 1 Nov 2016). 
34. Aromaa A, Klaukka T, Impivaara O, et al. Aikuisten työ- ja toimintakyky sekä avuntarve. In: Aromaa A, Heliövaara M, Impivaara O et al (Eds.), Health, Functional Limitations and Need for Care in Finland. Basic Results from the Mini-Finland Health Survey. Helsinki and Turku; Publications of the Social Insurance Institution of Finland AL 32;1989:355-66,751.

35. Katz S, Ford AB, Moskowitz RW, et al. Studies of illness in the aged. The index of ADL: a standardized measure of biological and psychosocial function. J Am Med Assoc 1963;185:914-19.

36. Lawton MP, Brody EM. Assessment of older people: self-maintaining and instrumental activities of daily living. Gerontologist 1969;9:179-86.

37. Derogatis LR, Melisaratos N. The brief symptom inventory: an introductory report. Psychol Med 1983;13:595-605.

38. Helzberg JH, Waeckerle JF, Camilo J, et al. Comparison of cardiovascular and metabolic risk factors in professional baseball players versus professional football players. Am J Cardiol. 2010 (1);106(5):664-7.

39. Selden MA, Helzberg JH, Waeckerle JF, et al. Cardiometabolic abnormalities in current National Football League players. Am J Cardiol. 2009 (1);103(7):969-71.

40. Harmon KG, Asif IM, Maleszewski JJ, et al. Incidence and Etiology of Sudden Cardiac Arrest and Death in High School Athletes in the United States. Mayo Clin Proc. 2016;91(11):1493-1502.

41. Lee DC, Brellenthin AG, Thompson PD, Sui X, Lee IM, Lavie CJ. Running as a Key Lifestyle Medicine for Longevity. Prog Cardiovasc Dis 2017;60:45-55.

42. Aengevaeren VL, Mosterd A, Braber TL, et al. Relationship Between Lifelong Exercise Volume and Coronary Atherosclerosis in Athletes. Circulation. 2017;136(2):138-148.

43. Vartiainen E, Seppälä T, Lillsunde P, et al. Validation of self-reported smoking by serum nicotinine measurement in a community-based study. J Epidemiol Community Health 2002;56(3):167-70.

44. Poikolainen K. Underestimation of recalled alcohol intake in relation to actual consumption. Br J Addict. 1985;80:215-6. 
45. Kujala UM, Kaprio J, Rose RJ. Physical activity in adolescence and smoking in young adulthood: a prospective twin cohort study. Addiction 2007;102(7):1151-7.

473

474 


\section{List of Figures}

- Figure 1. Study profile

\section{List of Tables}

- Table 1. Number of participants at entry to study and still alive in 2001, and December 31, 2015.

- Table 2. Age-adjusted hazard ratios (HRs) for all-cause deaths from time of entry to December 31, 2015 among former athletes (n=900) compared to age-matched brothers $(n=900)$, mean $(\mathrm{SD})$ and median age at entry, median and mean age at death.

- Table 3. Demographic and lifestyle characteristics (physical activity, alcohol use and smoking) among former athletes ( $\mathrm{n}=199)$ and brothers $(n=199)$.

- Table 4. Self-rated health, diseases, functioning of daily living, mobility, self-rated mood and working status among former athletes ( $\mathrm{n}=199$ ) and brothers $(\mathrm{n}=199)$. 
Table 1. Number of participants at entry to study and still alive in 2001, and December 31, 2015.

\begin{tabular}{|c|c|c|c|c|c|c|c|c|c|}
\hline \multirow[t]{2}{*}{ Sports groups } & \multirow{2}{*}{$\begin{array}{c}\text { Participants } \\
\text { at entry } \\
\text { N }\end{array}$} & \multicolumn{2}{|c|}{$\begin{array}{c}\text { Participants at entry } \\
\text { included in statistical } \\
\text { analysis }\end{array}$} & \multicolumn{2}{|c|}{ Participants alive in 2001} & \multicolumn{2}{|c|}{$\begin{array}{l}\text { Questionnaire responders } \\
\text { in } 2001 \text { included in statistical } \\
\text { analysis }\end{array}$} & \multicolumn{2}{|c|}{ Participants alive in 2015} \\
\hline & & $\mathbf{N}$ & Mean age (SD) & $\mathbf{N}$ & Mean age (SD) & $\mathbf{N}$ & Mean age (SD) & $\mathbf{N}$ & Mean age (SD) \\
\hline 1. Endurance & 341 & $217^{*}$ & $27.0(4.1)$ & 104 & $71.8(8.4)$ & 44 & $69.1(7.4)$ & 54 & $81.6(5.8)$ \\
\hline 2. Mixed sports & 941 & $307^{\dagger}$ & $23.0(3.0)$ & 177 & $67.4(8.7)$ & 80 & $66.0(8.1)$ & 106 & $78.0(5.8)$ \\
\hline 3. Power sports & 1142 & $376^{*}$ & $24.5(3.7)$ & 174 & $68.1(7.3)$ & 75 & $67.0(6.6)$ & 91 & $79.5(5.5)$ \\
\hline All athletes & 2424 & 900 & $24.6(3.9)$ & 455 & $68.7(8.3)$ & 199 & $67.1(7.5)$ & 251 & $79.3(5.8)$ \\
\hline Brothers & 2673 & 900 & $25.1(6.6)$ & 393 & $67.4(9.6)$ & 199 & $65.9(8.6)$ & 253 & $79.1(8.0)$ \\
\hline Total & 5097 & 1800 & $24.8(5.4)$ & 848 & $68.1(9.0)$ & 398 & $66.6(8.0)$ & 504 & $79.2(7.0)$ \\
\hline
\end{tabular}

Data are numbers at entry included statistical analysis

${ }^{*}$ Long distance running 95, middle distance running 45, cross-country skiing 77.

Soccer 75, ice hockey 33, basketball 22, high jump 17, pole vault 23, long jump 14, triple jump 15 , hurdling 36 , short-distance running 46 , decathlon 26 .

* Weight-lifting 43, Boxing 95, wrestling 155, shot-put 18, discus 15, javelin 32, hammer 19. 
Table 2. Age-adjusted hazard ratios (HRs) for all-cause deaths from time of entry to December 31, 2015 among former athletes ( $\mathrm{n}=900$ ) compared to age-matched brothers $(n=900)$, mean $(\mathrm{SD})$, median age at entry, median and mean age at death.

\begin{tabular}{|c|c|c|c|c|c|c|}
\hline Sports groups & $\begin{array}{c}\text { Mean age (SD) } \\
\text { at entry }\end{array}$ & Median age at entry & $\begin{array}{c}\text { Median age at death } \\
(95 \% \mathrm{CI}) \\
\end{array}$ & Mean age at death $(95 \% \mathrm{CI})$ & $\begin{array}{c}\text { Age-adjusted HR } \\
(95 \% \mathrm{CI}) \\
\end{array}$ & P-value* \\
\hline Endurance $(\mathrm{n}=217)$ & $27.0(4.1)$ & 26.0 & $79.9(79.1-80.7)$ & $77.5(75.7-79.3)$ & $0.607(0.448-0.823)$ & 0.001 \\
\hline Mixed sports ( $n=307)$ & $23.0(3.0)$ & 23.0 & $75.9(75.1-76.7)$ & 73.3(72.0-75.4) & $0.848(0.652-1.104)$ & 0.220 \\
\hline Power sports $(n=376)$ & $24.5(3.7)$ & 24.0 & $74.1(73.3-75.0)$ & $72.2(70.7-73.3)$ & $0.779(0.619-0.980)$ & 0.033 \\
\hline All athletes $(\mathrm{n}=900)$ & $24.6(3.9)$ & 24.0 & $75.9(75.1-76.7)$ & $74.0(73.0-75.0)$ & $0.753(0.648-0.875)$ & $<0.001$ \\
\hline Brothers $(\mathrm{n}=900)$ & $25.1(6.6)$ & 25.0 & $73.0(72.0-74.0)$ & $69.9(68.7-71.0)$ & 1.000 & - \\
\hline
\end{tabular}

*p-values for statistical differences between sports groups and brothers by a paired Cox regression analysis. 
Table 3. Demographic and lifestyle characteristics (physical activity, alcohol use and smoking) among former athletes $(n=199)$ and brothers $(n=199)$.

\begin{tabular}{|c|c|c|c|}
\hline & Former athletes $(\mathrm{N}=199)$ & Brothers (N=199) & P-value \\
\hline Age (mean (SD)), years* & $67.1(7.5)$ & $65.9(8.6)$ & $0.007^{\mathrm{a}}$ \\
\hline Marital status \%(n)* & & & $0.035^{\mathrm{b}}$ \\
\hline Single & $1.0(2)$ & $4.5(9)$ & \\
\hline Married & $69.7(138)$ & $77.4(154)$ & \\
\hline Remarried & $6.6(13)$ & $3.5(7)$ & \\
\hline Cohabiting & $8.1(16)$ & $3.5(7)$ & \\
\hline Divorced & $8.1(16)$ & $4.5(9)$ & \\
\hline Widowed & $6.6(13)$ & $6.5(13)$ & \\
\hline \multicolumn{4}{|l|}{ Anthropometric data } \\
\hline Height, m, mean ( $95 \%$ CI) & 175.9(174.8-177.0) & $175.1(174.2-176.0)$ & $0.13^{\mathrm{a}}$ \\
\hline Weight, kg, mean ( 95\% CI) & $81.4(79.6-83.3)$ & $81.4(79.7-83.1)$ & $0.94^{\mathrm{a}}$ \\
\hline $\begin{array}{l}\text { Mean BMI, } \mathrm{kg} / \mathrm{m}^{2}(95 \% \\
\text { CI) }\end{array}$ & $26.2(25.8-26.7)$ & $26.5(26.0-27.0)$ & $0.41^{\mathrm{a}}$ \\
\hline \multicolumn{4}{|l|}{ Physical activity } \\
\hline $\begin{array}{l}\text { Mean MET- } \\
\text { hours/day }(95 \% \mathrm{CI}) *\end{array}$ & $4.4(3.7-5.1)$ & $3.2(2.7-3.6)$ & $0.012^{\mathrm{a}}$ \\
\hline $\begin{array}{l}\text { Physical Activity tertiles }{ }^{\dagger} \\
\% \text { (n) }\end{array}$ & & & $0.734^{\mathrm{a}}$ \\
\hline Less active & $34.7(69)$ & $37.7(75)$ & \\
\hline Moderately active & $38.2(76)$ & $29.1(58)$ & \\
\hline Highly active & 27.1(54) & $33.2(66)$ & \\
\hline \multicolumn{4}{|l|}{ Types of physical activity } \\
\hline $\begin{array}{l}\text { No physical activity } \\
\text { Walking } \\
\text { Walking and jogging } \\
\text { Jogging } \\
\text { Brisk running }\end{array}$ & $\begin{array}{l}3.6(7) \\
45.2(89) \\
32.0(63) \\
8.1(16) \\
11.2(22)\end{array}$ & $\begin{array}{l}3.1(6) \\
63.4(127) \\
20.6(40) \\
10.8(21) \\
2.1(4)\end{array}$ & $0.001^{\mathrm{a}}$ \\
\hline \multicolumn{4}{|l|}{ Sedentary lifestyle } \\
\hline $\begin{array}{l}\text { Mean sitting time } \\
\text { hours/day }(95 \% \mathrm{CI})^{*}\end{array}$ & $5.3(4.9-5.7)$ & $6.3(5.8-6.7)$ & $<0.001$ \\
\hline \multicolumn{4}{|l|}{ Smoking } \\
\hline Smoking status, \% (n)* & & & $2.57 \mathrm{e}^{-04 \mathrm{a}}$ \\
\hline$\overline{\text { Current smoker }}$ & 7.1(14) & 13.9(27) & \\
\hline Occasional smoker & $1.0(2)$ & $2.1(4)$ & \\
\hline Ex-smoker & $25.9(51)$ & $39.2(76)$ & \\
\hline Never smoker & $66.0(130)$ & $44.8(87)$ & \\
\hline $\begin{array}{l}\text { Heaviness of smoking index } \\
\text { (HSI, range } 0-6), \text { mean }\end{array}$ & & & 0.004 \\
\hline \multicolumn{4}{|l|}{$(\mathrm{SD})^{*}$} \\
\hline among current / ex-smokers & $1.5(1.6) / 1.4(1.8)$ & $2.0(1.7) / 1.3(1.5)$ & \\
\hline
\end{tabular}




\section{Alcohol}

Total alcohol consumption 184.9(136.2-233.6)

$0.58^{\mathrm{a}}$

g/month (mean, $95 \% \mathrm{CI}$ )

Type of alcohol drinker

$\%(\mathrm{n})$

Abstainer or light drinker

$67.3(134)$

$60.3(120)$

Moderate drinker

21.1(42)

25.6(51)

Heavy drinker

$11.6(23)$

$14.1(28)$

Heavy drinking occasions

(HDO) \% (n)

$65.8(129)$

65.3(126)

$0.70^{\mathrm{b}}$

At least once a week

10.2(20)

1-2 times a month

$16.3(32)$

16.1(31)

No HDO

$73.5(144)$

18.1(35)

$65.8(127)$

${ }^{*} \mathrm{p}<0.05$ for statistical differences between athletes and age-matched brothers by a) Wilcoxon`s signed rank -test or ${ }^{\text {b) }}$ McNemar`s test.

$\dagger$ Overall physical activity (MET-hours/day): MET-hours/day $\leq 2.3$ are less active, $2.3<$ MET-hours/day $\leq 4.5$ are moderately active) and MET-hours/day > 4.5 are highly active. 
Table 4. Self-rated health, diseases, functioning of daily living, mobility, self-rated mood and working status among former athletes $(n=199)$ and brothers $(n=199)$.

$\begin{array}{lll}\begin{array}{l}\text { Former athletes } \\ (n=199)\end{array} & \begin{array}{l}\text { Brothers } \\ (n=199)\end{array} & \text { P-value }\end{array}$

Self-rated health (SRH) \%(n)*

$3.3 \mathrm{e}^{-04 a}$

Very good

$20.6(41)$

48.7(97)

26.1(52)

Average

$4.5(9)$

Quite poor or poor

$48.0(95)$

$34.8(69)$

$8.6(17)$

\section{Diseases \%(n)}

Self-reported any chronic disease*

$52.8(102)$

$0.039^{\mathrm{b}}$

Physician-diagnosed chronic disease

Hypertension with medication

33.7(67)

40.1(79)

$0.12^{b}$

17.2(25)

17.4(26)

$0.13^{\mathrm{b}}$

Myocardial infarct

$10.6(21)$

11.1(22)

$0.86^{\mathrm{b}}$

Diabetes

$3.5(7)$

6.1(12)

$0.16^{\mathrm{b}}$

Kidney disease

$4.0(5)$

$14.8(20)$

2.7(9)

$0.74^{\mathrm{b}}$

Ulcer

10.4(14)

17.9(26)

$0.84^{\mathrm{b}}$

Asthma

43.5(70)

14.7(21)

$0.59^{\mathrm{b}}$

Osteoarthritis

Sports injuries \%(n)

Any sports injury*

26.3(52)

Achilles tendinitis*

21.1(37)

$4.9(8)$

$37.0(57)$

$0.32^{\mathrm{b}}$

Achilles total rupture

Mobility \%(n)

No restrictions

$84.3(161)$

16.3(32)

$0.021^{\mathrm{b}}$

6.1(10)

$0.003^{\mathrm{b}}$

$1.9(3)$

$0.21^{\mathrm{b}}$

No ancillaries

With ancillaries

Functioning of daily living ${ }^{\dagger}$

Physical (score range 5-20), mean (95\% CI)

Physical, good functionality \%(n)

$14.7(28)$

79.4(154)

$1.8(2)$

19.1(37)

$1.5(3)$

5.5(5.3-5.8)

$5.8(5.5-6.1)$

$0.211^{\mathrm{a}}$

$98.0(195)$

97.5(194)

$0.74^{\mathrm{b}}$

Physical, poor functionality \%(n)

2.0(4)

$2.5(5)$

Psychosocial (score range 4-16), mean

5.2(4.9-5.2)

$5.3(5.0-5.5)$

$0.74^{\mathrm{a}}$ (95\% CI)

Psychosocial, good functionality\% (n) 98.5(196)

Psychosocial, poor functionality\% (n) 1.5(3)

98.5(194)

$1.000^{\mathrm{b}}$

$1.5(3)$

Self-rated mood (BSI-53)

Depression, mean $(95 \% \mathrm{CI})$

2.1(1.7-2.5)

2.6(2.1-3.1)

$0.28^{\mathrm{a}}$

Depression, \% (n) with high score $(\geq 8)$

$6.5(13)$

$8.5(17)$

$0.43^{\mathrm{b}}$

Anxiety, mean $(95 \% \mathrm{CI}) *$

2.1(1.7-2.4)

2.7(2.3-3.1)

$0.048^{\mathrm{a}}$

Anxiety, \%(n), with high score $(\geq 7)$

7.7(15)

$0.59^{\mathrm{b}}$ 
Working status \%(n)

Employed

15.6(31)

19.6(39)

On old age pension

$57.8(115)$

$50.8(101)$

On disability pension

13.1(26)

18.6(37)

Unemployed

$4.0(8)$

$3.0(6)$

Other

9.5(19)

$8.0(16)$

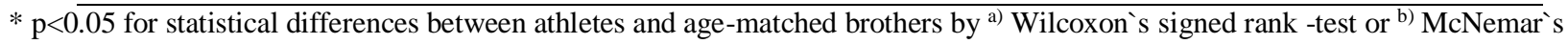
test.

${ }^{\dagger}$ Functioning of daily living (Activities of daily living scales (Mini-Finland Health Survey):

Physical Two groups: $0=$ good functioning, score 1 or $2,1=$ poor functioning, score 3 or 4 on any item

Psychological Two groups: $0=$ good functioning, score 1 or $2,1=$ poor functioning, score 3 or 4 on any item

${ }^{\ddagger}$ Self-rated mood (Shortened anxiety and depression scales of BSI-53):

Depression Two groups: $0=$ no depressive, score $\leq 7.99,1=$ depressive, score $\geq 8$

Anxiety Two groups: $0=$ no anxious, score $\leq 6.99,1=$ anxious, score $\geq 7$

\section{Self-rated mood:}

The participants were asked to rate their mood at this moment on a 5-point Likert scale of 0-4: never (0), seldom (1), sometimes (2), often (3), and very often (4). So, the range of the sum scores was 0-24. The highest decile of the outcome variable (depression or anxiety) was considered an abnormal outcome, with others classified as not affected for the purposes of analyzing presence of a possible mood disorder. However, the scales are not diagnostic of clinical disease. 


\section{List of Supplementary Tables}

- Table 1 Socioeconomic status (SES) among former athletes (n=900) and their age-matched brothers (n=900).

- Table 2 Causes of death among former athletes $(n=900)$ and their age-matched brothers $(n=900)$.

- Table 3 Age-adjusted hazard ratios (HRs) for all-cause deaths from time of entry to December 31, 2015 among former athletes (n=900) compared to age-matched brothers $(n=1855)$, mean (SD) and median age at entry, median and mean age at death.

- Tables 4a-d Age-adjusted hazard ratios (HRs) for all-cause deaths, when the follow up time was divided into two periods: age at entry to median age at death and median age at death to December 31, 2015.

- Table 5 Age-, BMI-, MET-index-, alcohol- and smoking-adjusted hazard ratios (HRs) for all-cause deaths starting from the questionnaire 2001 to death, migration or end of follow-up (December 31,2015) among former athletes and controls compared to brothers.

- Table 6 Demographic and lifestyle characteristics (physical activity, alcohol use and smoking) among 199 former athletes, 322 brothers and 416 controls.

- Table 7 Self-rated health, diseases, functioning of daily living, mobility, self-rated mood and working status among 199 former athletes, 322 brothers and 416 controls. 
Table 1 Socioeconomic status (SES) among former athletes $(n=900)$ and their age-matched brothers $(n=900)$

\begin{tabular}{lcc}
\hline Socioeconomic status* & Former athletes \%(n) & Brothers \%(n) \\
\hline Executives & $20.9(188)$ & $11.3(43)$ \\
White collar & $38.2(344)$ & $24.7(94)$ \\
Blue collar & $30.3(273)$ & $42.1(160)$ \\
Farmer & $7.5(68)$ & $13.9(53)$ \\
Unskilled worker & $2.9(26)$ & $6.8(26)$ \\
Other & $0.2(2)$ & $1.1(4)$ \\
Status unknown & $0.8(7)$ & $58.1(528)$ \\
\hline
\end{tabular}

* $\mathrm{p}<0.001$ for group differences in socioeconomic status by $\chi^{2}$-test and McNemar`s test. 
Table 2 Causes of death among former athletes $(n=900)$ and their age-matched brothers $(n=900)$.

\begin{tabular}{lcc}
\hline \multicolumn{1}{c}{ Causes of death* } & $\begin{array}{c}\text { Athletes } \\
\text { \%(n) }\end{array}$ & $\begin{array}{c}\text { Brothers } \\
\text { \%(n) }\end{array}$ \\
\hline (IHD) mortality & $34.3(219)$ & $36.9(199)$ \\
stroke mortality & $8.6(55)$ & $10.0(54)$ \\
cancer mortality & $20.1(128)$ & $16.1(87)$ \\
smoking-related cancer mortality & $4.1(26)$ & $5.4(29)$ \\
dementia mortality & $6.0(38)$ & $4.6(25)$ \\
alcohol-related causes (code 41; & $2.5(16)$ & $2.0(11)$ \\
alcohol-related diseases or & & \\
accidental poisoning by alcohol) & & \\
other disease mortality & $17.1(109)$ & $15.8(85)$ \\
\hline mortality for natural causes & $92.2(546)$ & $91.3(494)$ \\
mortality for external causes & $7.8(92)$ & $8.7(45)$ \\
(including injury, suicide etc.) & \multicolumn{2}{c}{$0.4(2)$} \\
\hline Unknown cases & $0.3(2)$ & $100.0(539)$ \\
\hline Total & \multicolumn{2}{c}{$100.0(638)$} \\
Missing data
\end{tabular}


Table 3 Age-adjusted hazard ratios (HRs) for all-cause deaths from time of entry to December 31, 2015 among former athletes (n=900) compared to age-matched brothers $(\mathrm{n}=1855)$, mean $(\mathrm{SD})$ and median age at entry, median and mean age at death.

\begin{tabular}{|c|c|c|c|c|c|c|}
\hline Sports groups & $\begin{array}{c}\text { Mean age (SD) at } \\
\text { entry }\end{array}$ & Median age at entry & $\begin{array}{c}\text { Median age at death } \\
(95 \% \mathrm{CI})\end{array}$ & Mean age at death $(95 \% \mathrm{CI})$ & $\begin{array}{c}\text { Age-adjusted HR } \\
\text { (95\% CI) }\end{array}$ & P-value* \\
\hline Endurance $(\mathrm{n}=217)$ & $27.0(4.1)$ & 26.0 & $79.9(79.1-80.7)$ & $77.5(75.7-79.3)$ & $0.607(0.472-0.780)$ & $<0.001$ \\
\hline Mixed sports $(\mathrm{n}=307)$ & $23.0(3.0)$ & 23.0 & $75.9(75.1-76.7)$ & 73.3(72.0-75.4) & $0.906(0.722-1.136)$ & 0.392 \\
\hline Power sports $(\mathrm{n}=376)$ & $24.5(3.7)$ & 24.0 & 74.1(73.3-75.0) & $72.2(70.7-73.3)$ & $0.763(0.631-0.923)$ & 0.005 \\
\hline All athletes (n=900) & $24.6(3.9)$ & 24.0 & $75.9(75.1-76.7)$ & $74.0(73.0-75.0)$ & $0.757(0.667-0.858)$ & $<0.001$ \\
\hline Brothers $(\mathrm{n}=1855)$ & $25.3(8.9)$ & 25.0 & $72.5(71.5-73.5)$ & $69.6(68.8-70.5)$ & 1.000 & - \\
\hline
\end{tabular}

*p-values for statistical differences between sports groups and brothers by Cox regression analysis. 
Tables 4a-d, Age-adjusted hazard ratios (HRs) for all-cause deaths, when the follow up time was divided into two periods: age at entry to median age at death and median age at death to December 31, 2015.

Table 4a Age-adjusted hazard ratios (HRs) for all-cause deaths from age at entry until the median age at death (74.35 years) or death or migration prior to that overall median age among former athletes $(n=900)$ compared to age-matched brothers $(n=900)$.

\begin{tabular}{cccc}
\hline Groups & $\begin{array}{c}\text { Median age at death } \\
(\mathbf{9 5 \%} \mathbf{~ C I})\end{array}$ & $\begin{array}{c}\text { Age-adjusted HR } \\
(\mathbf{9 5 \%} \mathbf{C I})\end{array}$ & P-value* \\
\hline All athletes $(\mathrm{n}=900)$ & $75.9(75.1-76.7)$ & $0.683(0.567-0.823)$ & $<0.001$ \\
Brothers $(\mathrm{n}=900)$ & $69.9(68.9-70.9)$ & 1.000 & - \\
\hline
\end{tabular}

*p-values for statistical differences between sports groups and brothers by a paired Cox regression analysis.

Table 4b Age-adjusted hazard ratios (HRs) for all-cause deaths starting from the median age at death (74.35 years) to death, migration or end of follow-up (December 31, 2015) among former athletes ( $\mathrm{n}=549)$ compared to age-matched brothers $(\mathrm{n}=480)$.

\begin{tabular}{cccc}
\hline Groups & $\begin{array}{c}\text { Median age at death } \\
(\mathbf{9 5 \%} \text { CI) }\end{array}$ & $\begin{array}{c}\text { Age-adjusted HR } \\
\mathbf{9 5 \%} \text { CI) }\end{array}$ & P-value* \\
\hline All athletes $(\mathrm{n}=549)$ & $82.2(81.8-82.6)$ & $0.744(0.566-0.977)$ & 0.033 \\
Brothers $(\mathrm{n}=480)$ & $81.0(80.5-81.5)$ & 1.000 & - \\
\hline
\end{tabular}

*p-values for statistical differences between sports groups and brothers by a paired Cox regression analysis. 
Table 4c Age-adjusted hazard ratios (HRs) for all-cause deaths from age at entry until the median age at death (73.67 years) or death or migration prior to that overall median age among former athletes $(n=900)$ compared to all brothers $(n=1855)$.

\begin{tabular}{cccc}
\hline Groups & $\begin{array}{c}\text { Median age at death } \\
(\mathbf{9 5 \%} \text { CI) }\end{array}$ & $\begin{array}{c}\text { Age-adjusted HR } \\
(\mathbf{9 5 \%} \text { CI) }\end{array}$ & P-value* \\
\hline All athletes $(\mathrm{n}=900)$ & $75.9(75.1-76.7)$ & $0.681(0.578-0.802)$ & $<0.001$ \\
Brothers $(\mathrm{n}=1855)$ & $72.5(71.5-73.5)$ & 1.000 & - \\
\hline
\end{tabular}

*p-values for statistical differences between sports groups and brothers by a paired Cox regression analysis.

Table 4d Age-adjusted hazard ratios (HRs) for all-cause deaths starting from the median age at death (73.67 years) to death, migration or end of follow-up (December 31, 2015) among former athletes $(n=571)$ compared to all brothers $(n=975)$.

\begin{tabular}{cccc}
\hline Groups & $\begin{array}{c}\text { Median age at death } \\
(\mathbf{9 5 \%} \mathbf{C I})\end{array}$ & $\begin{array}{c}\text { Age-adjusted HR } \\
\mathbf{9 5 \%} \mathbf{C I})\end{array}$ & P-value* \\
\hline All athletes $(\mathrm{n}=571)$ & $82.0(81.6-82.4)$ & $0.845(0.683-1.047)$ & 0.124 \\
Brothers $(\mathrm{n}=975)$ & $81.1(80.7-81.5)$ & 1.000 & - \\
\hline
\end{tabular}

*p-values for statistical differences between sports groups and brothers by a paired Cox regression analysis. 
Table 5 Age-, BMI-, MET-index-, alcohol- and smoking-adjusted hazard ratios (HRs) for all-cause deaths starting from the questionnaire 2001 to death, migration or end of follow-up (December 31, 2015) among former athletes $(n=785)$ and controls $(n=416)$ compared to brothers $(n=567)$.

\begin{tabular}{|c|c|c|c|c|c|c|c|c|c|c|c|c|}
\hline Groups & $\begin{array}{l}\text { Age-adjusted HR } \\
(95.0 \% \mathrm{CI})\end{array}$ & P-value* & $\begin{array}{l}\text { Age- and BMI- } \\
\text { adjusted } \\
\text { HR }(95.0 \% \mathrm{CI})\end{array}$ & P-value* & $\begin{array}{l}\text { Age- and MET- } \\
\text { index-adjusted } \\
\text { HR } \\
(95.0 \% \mathrm{CI})\end{array}$ & P-value* & $\begin{array}{l}\text { Age- and alcohol- } \\
\text { adjusted HR } \\
(95.0 \% \mathrm{CI})\end{array}$ & P-value* & $\begin{array}{l}\text { Age- and } \\
\text { smoking-adjusted } \\
\text { HR }(95.0 \% \mathrm{CI})\end{array}$ & P-value* & $\begin{array}{l}\text { Age-, BMI, MET- } \\
\text { index-, alcohol- and } \\
\text { smoking-adjusted } \\
\text { HR ( } 95.0 \% \text { CI) }\end{array}$ & P-value* \\
\hline All athletes $(\mathrm{n}=785)$ & $1.027(0.866-1.217)$ & 0.763 & $1.021(0.860-1.212)$ & 0.812 & $1.072(0.896-1.283)$ & 0.446 & $1.032(0.862-1.234)$ & 0.734 & $1.122(0.945-1.331)$ & 0.188 & $1.123(0.791-1.240)$ & 0.226 \\
\hline Controls $(\mathrm{n}=416)$ & $1.064(0.857-1.321)$ & 0.577 & $1.054(0.849-1.310)$ & 0.629 & $1.039(0.831-1.299)$ & 0.735 & $1.063(0.856-1.322)$ & 0.579 & $1.040(0.841-1.286)$ & 0.716 & $0.990(0.791-1.240)$ & 0.933 \\
\hline Brothers $(\mathrm{n}=567)$ & 1.000 & - & 1.000 & - & 1.000 & - & 1.000 & - & 1.000 & - & & \\
\hline
\end{tabular}

*p-values for statistical differences between sports groups and brothers by Cox regression analysis adjusted for family clustering. 
Table 6 Demographic and lifestyle characteristics (physical activity, alcohol use and smoking) among 199 former athletes, 322 brothers and 416 controls.

\begin{tabular}{|c|c|c|c|c|}
\hline & $\begin{array}{l}\text { Former athletes } \\
(\mathrm{N}=199)\end{array}$ & $\begin{array}{l}\text { Brothers } \\
(\mathrm{N}=322)\end{array}$ & P-value & $\begin{array}{l}\text { Population control } \\
(\mathrm{N}=416)\end{array}$ \\
\hline Age (mean (SD)), years* & $67.1(7.5)$ & $64.9(9.1)$ & $0.026^{\mathrm{b}}$ & $67.4(7.0)$ \\
\hline Marital status \%(n)* & & & $0.014^{\mathrm{a}}$ & \\
\hline Single & $1.0(2)$ & $6.5(21)$ & & $5.5(23)$ \\
\hline Married & $69.7(138)$ & $74.1(239)$ & & $71.4(297)$ \\
\hline Remarried & $6.6(13)$ & $4.0(13)$ & & $4.3(18)$ \\
\hline Cohabiting & $8.1(16)$ & $3.7(12)$ & & $4.8(20)$ \\
\hline Divorced & $8.1(16)$ & $5.9(19)$ & & $4.8(20)$ \\
\hline Widowed & $6.6(13)$ & $5.6(18)$ & & $9.1(38)$ \\
\hline \multicolumn{5}{|l|}{ Anthropometric data } \\
\hline Height, $\mathrm{cm}$, mean $(95 \% \mathrm{CI})$ & $175.9(174.8-177.0)$ & $175.1(174.4-175.8)$ & $0.099^{\mathrm{b}}$ & $175.2(174.6-175.8)$ \\
\hline Weight, kg, mean ( $95 \% \mathrm{CI})$ & $81.4(79.6-83.3)$ & $81.0(79.7-82.3)$ & $0.91^{\mathrm{b}}$ & $82.5(81.2-83.7)$ \\
\hline $\begin{array}{l}\text { BMI, } \mathrm{kg} / \mathrm{m}^{2} \text {, mean }(95 \% \\
\mathrm{CI})\end{array}$ & $26.2(25.8-26.7)$ & $26.1(25.6-26.5)$ & $0.52^{\mathrm{b}}$ & $26.8(26.4-27.2)$ \\
\hline $\begin{array}{l}\text { Physical activity } \\
\text { Mean MET- } \\
\text { hours/day (95\% CI)* }\end{array}$ & $4.4(3.7-5.1)$ & $3.3(2.9-3.7)$ & 0.005 & $2.4(2.1-2.7)$ \\
\hline \multicolumn{5}{|l|}{ Physical Activity tertiles ${ }^{\dagger} \%$} \\
\hline Less active & $29.9(59)$ & $38.8(125)$ & & $53.3(213)$ \\
\hline Moderately active & $28.6(57)$ & $30.7(99)$ & & $26.8(107)$ \\
\hline Highly active & $41.7(83)$ & $30.4(98)$ & & $20.0(80)$ \\
\hline $\begin{array}{l}\text { Types of physical activity } \\
\%(\mathrm{n})\end{array}$ & & & $7.5 \mathrm{e}^{-05 a}$ & \\
\hline No physical activity & $3.6(7)$ & $2.2(7)$ & & $9.5(38)$ \\
\hline Walking & $45.2(89)$ & $62.7(197)$ & & $72.1(290)$ \\
\hline Walking and jogging & $32.0(63)$ & $19.4(62)$ & & $11.9(48)$ \\
\hline Brisk running & $11.2(22)$ & $4.5(14)$ & & $1.5(6)$ \\
\hline \multicolumn{5}{|l|}{ Sedentary lifestyle } \\
\hline $\begin{array}{l}\text { Mean sitting time, hour/day } \\
(95 \% \mathrm{CI})^{*}\end{array}$ & $5.3(4.9-5.7)$ & $6.2(5.9-6.5)$ & $<0.001$ & $6.0(5.7-6.2)$ \\
\hline \multicolumn{5}{|l|}{ Smoking } \\
\hline Smoking status, $\%(\mathrm{n}) *$ & & & $2.13 \mathrm{e}^{-04 \mathrm{a}}$ & \\
\hline Current smoker & 7.1(14) & $13.3(42)$ & & $17.3(70)$ \\
\hline Occasional smoker & $1.0(2)$ & $1.6(5)$ & & $1.5(6)$ \\
\hline Ex-smoker & $25.9(51)$ & $40.0(126)$ & & $44.7(180)$ \\
\hline Never smoker & $66.0(130)$ & $45.1(142)$ & & $36.5(147)$ \\
\hline $\begin{array}{l}\text { Heaviness of smoking index } \\
\begin{array}{ll}\text { (HSI, range } & 0-6), \text { mean } \\
\text { (SD) }\end{array}\end{array}$ & & & & \\
\hline among current / ex-smokers & $1.5(1.6) / 1.4(1.8)$ & $2.1(1.5) / 1.9(1.5)$ & $0.16^{\mathrm{b}}$ & $2.6(1.4) / 1.8(1.6)$ \\
\hline
\end{tabular}




\section{Alcohol}

Total alcohol consumption g/month (mean, 95\% CI)

Type of alcohol drinker \% (n)

Abstainer or light drinker

$67.3(134)$

$62.1(200)$

$0.45^{\mathrm{a}}$

$57.2(238)$

Moderate drinker

21.1(42)

$25.5(82)$

27.6(115)

Heavy drinker

$11.6(23)$

$12.4(40)$

15.1(63)

Heavy drinking occasions

(HDO) \% (n)

$0.13^{\mathrm{a}}$

At least once a week

$10.2(20)$

15.7(49)

$16.8(67)$

1-2 times a month

16.3(32)

$18.6(58)$

$16.6(66)$

No HDO

$73.5(144)$

$65.7(205)$

$66.6(265)$

$* \mathrm{p}<0.05$ for statistical differences between athletes and theirbrothers by ${ }^{\text {a) }}$ the Chi square -test for categorical variables and ${ }^{\text {b) }}$ the Mann-Whitney-Utest for continuous variables.

†verall physical activity (MET-hours/day): MET-hours/day $\leq 1.5$ are less active, $1.5<$ MET-hours/day $\leq 4.0$ are moderately active and MET-

hours/day $>4.0$ are highly active 
Table 7 Self-rated health, diseases, functioning of daily living, mobility, self-rated mood and working status among 199 former athletes, 322 brothers and 416 controls.

\begin{tabular}{|c|c|c|c|c|}
\hline & $\begin{array}{l}\text { Former athletes } \\
(n=199)\end{array}$ & $\begin{array}{l}\text { Brothers } \\
(\mathrm{n}=322)\end{array}$ & P-value & $\begin{array}{l}\text { Population control } \\
(\mathrm{N}=416)\end{array}$ \\
\hline \multicolumn{3}{|l|}{ Self-rated health (SRH) \%(n)* } & $0.003^{\mathrm{a}}$ & \\
\hline Very good & $20.6(41)$ & $9.7(31)$ & & $7.0(29)$ \\
\hline Quite good & $48.7(97)$ & $50.9(164)$ & & $37.8(156)$ \\
\hline Average & $26.1(52)$ & $31.3(100)$ & & $42.9(177)$ \\
\hline Quite or very poor & $4.5(9)$ & $8.2(31)$ & & $12.4(51)$ \\
\hline \multicolumn{5}{|l|}{ Diseases \%(n) } \\
\hline Self-reported any chronic disease & $43.2(83)$ & $50.2(158)$ & $0.11^{\mathrm{a}}$ & $58.4(236)$ \\
\hline \multicolumn{5}{|l|}{ Physician-diagnosed chronic disease } \\
\hline Hypertension with medication & $33.7(67)$ & $36.5(117)$ & $0.63^{\mathrm{a}}$ & $38.6(159)$ \\
\hline Angina pectoris & $17.2(25)$ & $17.7(44)$ & $0.98^{\mathrm{a}}$ & $22.6(65)$ \\
\hline Myocardial infarct & $10.6(21)$ & $10.3(34)$ & $0.99^{\mathrm{a}}$ & $13.5(56)$ \\
\hline Diabetes & $3.5(7)$ & $5.0(17)$ & $0.52^{\mathrm{a}}$ & $9.0(37)$ \\
\hline Kidney disease & $4.0(5)$ & $7.8(17)$ & $0.17^{\mathrm{a}}$ & $6.2(15)$ \\
\hline Ulcer & $14.8(20)$ & $18.4(43)$ & $0.39^{\mathrm{a}}$ & $29.8(59)$ \\
\hline Asthma & $10.4(14)$ & $14.4(33)$ & $0.29^{\mathrm{a}}$ & $17.7(47)$ \\
\hline Osteoarthritis & $43.5(70)$ & $33.6(82)$ & $0.059^{\mathrm{a}}$ & 39.1(117) \\
\hline \multicolumn{5}{|l|}{ Sports injuries \%(n) } \\
\hline Any sports injury* & $26.3(52)$ & $15.2(49)$ & $0.002^{\mathrm{a}}$ & $7.6(31)$ \\
\hline Achilles tendinitis* & $21.1(37)$ & $5.6(15)$ & $2.0 \mathrm{e}^{-05 a}$ & $5.8(20)$ \\
\hline Achilles total rupture & $4.9(8)$ & $1.9(5)$ & $0.069^{\mathrm{a}}$ & $2.1(7)$ \\
\hline Mobility \%(n) & & & $0.72^{\mathrm{a}}$ & \\
\hline No restrictions & $84.3(161)$ & $81.3(257)$ & & $78.2(322)$ \\
\hline No ancillaries & $14.7(28)$ & $17.1(54)$ & & $18.9(78)$ \\
\hline With ancillaries & $1.8(2)$ & $1.6(5)$ & & $2.7(11)$ \\
\hline \multicolumn{5}{|l|}{ Functioning of daily living ${ }^{\dagger}$} \\
\hline $\begin{array}{l}\text { Physical (score range } 5-20) \text {, mean } \\
(95 \% \text { CI) }\end{array}$ & $5.5(5.3-5.8)$ & $5.8(5.6-6.0)$ & $0.24^{\mathrm{b}}$ & $6.3(6.1-6.6)$ \\
\hline Physical, good functionality \%(n) & $98.0(195)$ & $94.7(303)$ & $0.35^{\mathrm{a}}$ & $94.0(375)$ \\
\hline Physical, poor functionality \%(n) & $2.0(4)$ & $5.3(17)$ & & $6.0(24)$ \\
\hline $\begin{array}{l}\text { Psychosocial (score range } 4-16) \text {, } \\
\text { mean }(95 \% \mathrm{CI})\end{array}$ & $5.2(4.9-5.2)$ & $5.3(5.1-5.5)$ & $0.10^{\mathrm{b}}$ & $5.7(5.5-5.9)$ \\
\hline $\begin{array}{l}\text { Psychosocial, good functionality } \\
\% \text { (n) }\end{array}$ & $98.5(196)$ & $95.5(300)$ & $0.65^{\mathrm{a}}$ & $91.3(376)$ \\
\hline $\begin{array}{l}\text { Psychosocial, poor functionality } \% \\
\text { (n) }\end{array}$ & $1.5(3)$ & $4.5(16)$ & & $8.7(36)$ \\
\hline \multicolumn{5}{|l|}{ Self-rated mood (BSI-53) } \\
\hline Depression , mean (95\% CI) & $2.1(1.7-2.5)$ & $2.5(2.1-2.8)$ & $0.14^{b}$ & $3.1(2.8-3.4)$ \\
\hline $\begin{array}{l}\text { Depression, \% (n) with high score } \\
(\geq 8)\end{array}$ & $6.5(13)$ & $8.5(27)$ & $0.70^{\mathrm{a}}$ & $7.4(30)$ \\
\hline
\end{tabular}




\begin{tabular}{lllll} 
Anxiety, mean $(95 \% \mathrm{CI})^{*}$ & $2.1(1.7-2.4)$ & $2.7(2.3-3.0)$ & $0.008^{\mathrm{b}}$ & $3.0(2.7-3.3)$ \\
Anxiety, \%(n), with high score $(\geq 7)$ & $7.7(15)$ & $9.4(30)$ & $0.59^{\mathrm{a}}$ & $5.8(23)$ \\
& & & & \\
Working status \%(n) & & & $0.064^{\mathrm{a}}$ & \\
Employed & $15.6(31)$ & $23.1(74)$ & & $11.1(46)$ \\
On old age pension & $57.8(115)$ & $48.0(154)$ & & $53.4(222)$ \\
On disability pension & $13.1(26)$ & $18.7(60)$ & & $20.2(84)$ \\
Unemployed & $4.0(8)$ & $2.5(8)$ & & $4.1(17)$ \\
Other & $9.5(19)$ & $7.8(26)$ & & $11.3(47)$ \\
\hline
\end{tabular}

$* \mathrm{p}<0.05$ for statistical differences between athletes and age-matched brothers by ${ }^{\text {a) }}$ the Chi square -test for categorical variables and

b) the Mann-Whitney-U test for continuous variables.

${ }^{\dagger}$ Functioning of daily living (Activities of daily living scales (Mini-Finland Health Survey):

Physical Two groups: $0=$ good functioning, score 1 or 2, $1=$ poor functioning, score 3 or 4 on any item

Psychological Two groups: $0=$ good functioning, score 1 or $2,1=$ poor functioning, score 3 or 4 on any item

${ }^{\star}$ Self-rated mood (Shortened anxiety and depression scales of BSI-53):

Depression Two groups: $0=$ no depressive, score $\leq 7.99,1=$ depressive, score $\geq 8$

Anxiety Two groups: $0=$ no anxious, score $\leq 6.99,1=$ anxious, score $\geq 7$

Functioning of daily living:

According to Bäckmand et al (2010) questionnaire 2001 respondents were asked to assess their functional ability to perform each of the activities by choosing one of following alternatives: $1=\mathrm{I}$ perform this without difficulty, $2=$ with some difficulty, $3=$ with considerable difficulty, and $4=$ not at all. Then, it was defined those who reported poor function (score 3 or 4 ) for at least one of the tasks as having poor physical functioning, while others were classified as having normal functioning, and it was made likewise for psychosocial functioning.

Reference:

Bäckmand H, Kujala U, Sarna S, et al. Former athletes' health-related lifestyle behaviours and self-rated health in late adulthood. Int J Sports Med 2010;31(10):751-8.

Self-rated mood:

The participants were asked to rate their mood at this moment on a 5-point Likert scale of 0-4: never (0), seldom (1), sometimes (2), often (3), and very often (4). So, the range of the sum scores was 0-24. The highest decile of the outcome variable (depression or anxiety) was considered an abnormal outcome, with others classified as not affected for the purposes of analyzing presence of a possible mood disorder. However, the scales are not diagnostic of clinical disease. 